\title{
ASSOCIAÇÃO DE MICROBIOTA E USO DE PROBIÓTICOS AO CARCINOMA HEPATOCELULAR: REVISÃO SISTEMÁTICA
}

\author{
Caroline Pereira Modesto ${ }^{1}$; Lucas Tavares Cruz de Albuquerque ${ }^{1}$; Maria Rebeca Feitosa Ribeiro ${ }^{1}$; \\ Daianny Mesquita Ponte ${ }^{1}$; Cícero Robério Araújo Motta ${ }^{2}$.
}

Introdução: O carcinoma hepatocelular $(\mathrm{CHC})$ ou hepatocarcinoma representa cerca de $85 \%$ dos cânceres primários do fígado, sendo reconhecido por sua agressividade e elevadas taxas de mortalidade a partir do princípio dos sintomas. Estima-se uma sobrevida média inferior a um mês após o início das manifestações, caso não seja estabelecido um projeto terapêutico. Com base na baixa eficácia e restrição dos tratamentos disponíveis, novos estudos indicam que o desenvolvimento do CHC pode ser modulado pela microbiota intestinal, propondo uma nova perspectiva terapêutica a partir do uso de probióticos. Objetivo: Analisar a influência da microbiota e o uso de probióticos na hepatocarcinogênese. Método: Efetuou-se uma revisão sistemática sem metanálise a partir das bases de dados Scielo e PubMed com itens publicados no período de 2006 a 2015, em língua inglesa. Foram encontrados 16 artigos, dos quais apenas 3 foram escolhidos por seguirem os critérios definidos acima. Resultados: O eixo intestinofígado propicia vulnerabilidade hepática aos efeitos de altas concentrações de produtos tóxicos no sistema portal. Um estudo em modelo animal demonstrou que variações da microbiota enteral induz um aumento da produção de ácido desoxicólico (DCA) pelas bactérias patogênicas. Este metabólico é reconhecido pelas anomalias causadas ao DNA das células perissinusoidais do fígado, predispondo à liberação de produtos inflamatórios e progressão de tumores. Outro estudo para avaliar o uso de probióticos na redução da excreção urinária de aflatoxina-B1, elemento discernido como hepatocarcinogênico humano, evidenciou alterações significativas. Destaca-se a diminuição das taxas dessa toxina em 36\% na semana 3 e $55 \%$ na semana 5 de tratamento $(p=0,005)$ no grupo que fez uso de probióticos à base de Lactobacillus e Propionibacterium em detrimento do grupo placebo, constatando a possibilidade de bloqueio da absorção de aflatoxina a partir da administração de probióticos. Realizou-se uma pesquisa em pacientes submetidos à ressecção hepática para mensurar os efeitos pós-operatórios do uso de probióticos. O grupo em terapia probiótica apresentou apenas $3 \%$ de infecções pós-cirúrgicas versus $48 \%$ do grupo que recebeu somente fibras. Conclusão: As evidências apresentadas demonstram a influência da microbiota intestinal na hepatocarcinogênese, tornando a abordagem probiótica instrumento de prevenção ao desenvolvimento de $\mathrm{CHC}$ e infecções pósoperatórias em pacientes que realizaram ressecção hepática.

Palavras-chave (Keywords): Carcinoma hepatocelular (Hepatocellular carcinoma). Microbiota (Microbiota). Probióticos (Probiotics).

\footnotetext{
${ }^{1}$ Acadêmicos da Faculdade de Medicina Estácio Juazeiro do Norte.

2 Médico Gastroenterologista e professor orientador da Faculdade de Medicina Estácio Juazeiro do Norte.

Autor Correspondente: carolinepmodesto@ hotmail.com

12 Id on Line Rev. Mult. Psic. V.12, N. 40. 2018 - ISSN 1981-1179

EDIÇÃO ESPECIAL: I CURSO DE ONCOLOGIA DO CARIRI / II JORNADA DE PESQUISA QUANTI-QUALITATIVA EM ONCOLOGIA. JUAZEIRO DO NORTE, 05 A 10 DE MARÇO DE 2018.

Edição eletrônica em http://idonline.emnuvens.com.br/id
} 